\title{
Alma Karlin - svojevrstna pisateljska osebnost
}

\author{
SILVIJA BOROVNIK \\ Univerza v Mariboru, Filozofska fakulteta, Koroška cesta 160, \\ SI-2000 Maribor, silvija.borovnik@um.si
}

\begin{abstract}
Članek se ukvarja s svojevrstno pisateljsko osebnostjo Almo M. Karlin, rojeno v Celju, ki je bila poliglotka in avtorica številnih potopisov ter drugih literarnih del. Ta dela je, čeprav hči slovenskih staršev, napisala $v$ nemščini in $\mathrm{z}$ njimi $\mathrm{v}$ času pred drugo svetovno vojno dosegla mednarodno slavo. Bila je posebna ne le kot literarna ustvarjalka, temveč tudi kot upornica zoper ženske stereotipe svojega obdobja. Svet je prepotovala $\mathrm{v}$ času, ko je bilo samotno potovanje za žensko, ki se preživlja s pisanjem, nekaj popolnoma neobičajnega. Kot avtorica, ki je izvirala iz slovenskega okolja, a je pisala v nemškem jeziku, pa predstavlja tudi zanimiv primer medkulturne identitete. S svojimi literarnimi deli, od katerih večina ostaja še vedno neraziskanih, je kršila najrazličnejše klišeje in tabuje, zato jo uvrščamo med tiste osebnosti, ki so s svojo vztrajnostjo in ustvarjalnim pogumom zaznamovale 20. stoletje.
\end{abstract}

This article is concerned with a peculiar author, Alma Karlin, born in Celje. She was a polyglot and an author of numerous travelogues and other literary works. Although Alma Karlin was the daughter of Slovenian parents, she wrote in German, and before the second World War her work became internationally recognised and famous. Still, even in postmodern times, she represents an interesting case of intercultural identity. Alma Karlin was also an eternal rebel against female stereotypes in her own time. She has travelled the world in times, when this was considered rather odd and unusual for a self-employed female writer. With her literary works, many still unexplored, Alma Karlin broke numerous clichés and taboos. That is why she can be classified as one those special, persistent and courageous personas and writers that characterised the 20th century.

Ključne besede: Alma M. Karlin, literarna zgodovina, slovenska književnost, medkulturnost, žensko vprašanje

Key words: Alma M. Karlin, literary history, Slovene literature, interculturalism, women's issues 
Alma ${ }^{1}$ Maximiliana Karlin je bila rojena v slovenski družini v Celju. Bila je hči avstro-ogrskega častnika in matere, ki je bila po poklicu učiteljica. V družini so znali slovensko, a je bil jezik njenega vsakdanjega komuniciranja in poznejšega izobraževanja nemščina. Alma Karlin je bila poliglotka, svoja literarna dela in številne potopise, ki so že v času njenega življenja izhajali po Evropi in drugje po svetu, je napisala v nemščini. Njen opus obsega štiriindvajset knjig, več kot štirideset proznih del in pesmi pa je ostalo v rokopisu in je delno še vedno neraziskanih. Že kot otrok je kazala nadpovprečne sposobnosti, med katerimi je izstopalo zlasti njeno zanimanje za tuje jezike. Srednjo šolo je končala v Gradcu, študij pa je nadaljevala v Londonu, kjer je na Kraljevi akademiji diplomirala iz osmih jezikov. Želela si je postati raziskovalka tujih kultur in pisateljica. Ko je izbruhnila prva svetovna vojna, je odpotovala $\mathrm{v}$ Skandinavijo, ob koncu vojne pa se je vrnila v Celje, kjer je ustanovila prvo šolo za poučevanje tujih jezikov. S prihranki se je leta 1919 odpravila na dolgo potovanje okrog sveta, ki je trajalo kar osem let. S teh svojih potovanj, ki so jo zanesla tudi v predele sveta, kamor še ni stopila ženska noga, je nenehno pisala in svoja besedila objavljala $v$ najbolj branih časopisih svojega časa. $\mathrm{Na}$ potovanjih je bila sama, s pisalnim strojem, z znamenito eriko, in brez spremstva, njeno delo pa je bilo tudi antropološko, etnološko in etnografsko. Prepotovala je Peru, Panamo in druge države Srednje Amerike, pot jo je zanesla na Havaje in na Japonsko ter Kitajsko, pa tudi v Korejo, Avstralijo, na Novo Zelandijo, v Indonezijo, na Tajsko in v Burmo. S svojih poti je v domače Celje pošiljala različne predmete, ki jih hrani Pokrajinski muzej v Celju. Njena zadnja postaja je bila Indija, od koder se je leta 1928 vrnila domov k bolni materi. Alma Karlin je pisala potopise, romane, novele, pesmi, dramska dela in objavila številne članke. Zagotovo je bila najbolj plodovita in najbolj cenjena pisateljica svojega časa, tudi v mednarodnem, ne le v slovenskem merilu. Bila je predlagana za Nobelovo nagrado za književnost, ki pa je ni prejela. Za kaj takega so bili stereotipi o mestu ženske kot pisateljice v tedanjem svetu očitno še preveč togi. Naselila se je v Celju, pozneje pa v hiški na Pečovniku s svojo prijateljico, nemško slikarko Theo Schreiber Gamelin. Kot antifašistko jo je med vojno preganjal nemški gestapo, zato je pobegnila v partizane. Tam pa so jo hoteli kot pripadnico nemške nacionalne skupnosti likvidirati, a jo je rešila partizanska prijateljica. Po vojni je do smrti živela skromno in odmaknjeno življenje na Pečovniku. Zanimanje zanjo je iz ideoloških razlogov, bila je namreč nasprotnica komunizma, in zaradi pisanja v nemščini po drugi svetovni vojni v slovenskem prostoru usahnilo, a je v osemdesetih letih dvajsetega stoletja znova oživelo. Novejši raziskovalci in raziskovalke $\mathrm{v}$ njeni osebnosti vidijo izstopajočo intelektualko in pisateljico, zagotovo pa eno najbolj samosvojih in nenavadnih osebnosti, kar smo jih na Slovenskem kdaj koli poznali.

Njena potopisna knjiga Urok Južnega morja je v slovenskem prevodu izšla šele leta 1996 . V tridesetih letih, ko so po posameznih delih pričenjali izhajati

\footnotetext{
${ }^{1}$ Članek je nastal v okviru raziskovanja Programske skupine P6-0156 na Filozofski fa-
} kulteti Univerze v Mariboru. 
potopisi Alme Karlin, ženske še niso veliko potovale po svetu, kaj šele, da bi potovale same in z namenom, da bi s svojih potovanj tudi pisale. Evropa in svet poznata nekaj bolj ali manj osamljenih primerov, navadno pa so to bile ženske, ki so izvirale iz bogatejših slojev. Potopisi Alme Karlin pričajo tudi o tem, da je potovala sama, da je sledila svoji neizmerni želji po raziskovalnem delu in da se je brez podpore družine preživljala s skromnimi honorarji. Z literarnega vidika so ta besedila zelo zanimiva, saj izkazujejo pisateljičin smisel za oblikovanje berljive, napete, navadno duhovite zgodbe, pa tudi njeno željo po tem, da bi bralcu kar najbolj živo predstavila posebnosti tujih, takrat še popolnoma eksotičnih kultur.

Po vrnitvi v Celje leta 1928 je Karlinova zasnovala trilogijo, ki jo je tudi napisala. To so knjige Samotno potovanje, Urok Južnega morja in Doživeti svet. Zelo opazno je, da sta v vseh poudarjena položaj in vloga ženske, kar se kaže že v podnaslovih: Die Tragödie einer Frau / Tragedija neke ženske (v Samotnem potovanju); Erlebnisse und Abenteuer einer Frau im Reich des Inkas und im fernem Osten / Doživetja in pustolovščine ženske v cesarstvu Inkov in na Daljnem vzhodu; Als Frau allein unter Pflanzen und Menschenfressern, Sträflingen, Matrosen und Missionaren / Samotna ženska med rastlinami in ljudožerci, kaznjenci, mornarji in misijonarji. Že iz naštetega je dobro razvidno, da se je Alma Karlin zavedala svoje ženske posebnosti in svojega edinstvenega položaja popotujoče pisateljice in raziskovalke, na kar je bila tudi ponosna. Njene knjige so izhajale v dvajset tisoč izvodih, odzivi nanje pa so bili neverjetni. Avtorico so bralci zasipali s pismi, sledili so tudi prevodi njenih del v angleščino in finščino, sama pa je imela med letoma 1930 in 1933 vrsto predavanj na potopisne teme in javnih branj; navdušeni bralci so po Evropi ustanavljali celo »klube ljubiteljev Alme Karlin«, kakor piše Marijan Pušavec v spremni besedi $\mathrm{k}$ izidu njenega romana v slovenščini. Slovenski odziv na njeno delo pa je bil zelo slaboten. V zvezi z njeno osebnostjo je vselej obstajala neka ambivalenca - je »naša« ali ni. Bila je slovenskega porekla, pisala pa je v nemščini. Samo sebe je imenovala »državljanko sveta«, v času svojega življenja pa je zamenjala kar nekaj potnih listov - najprej je imela avstrijskega, nato je dobila jugoslovanskega (SHS) in po drugi svetovni vojni še slovenskega oz. potni list socialistične, povojne Jugoslavije. Prostor, v katerem je ustvarjala in pisala, pa je bil večkulturen in zlasti v meščanskem svetu njenega časa sta bila sonavzoča dva jezika, nemščina in slovenščina. Izbrala je nemščino, slovensko pa je znala toliko, da se je v tem jeziku lahko sporazumevala. Ko se je med drugo svetovno vojno skupaj s Slovenci znašla v nemškem zaporu v Celju, je obžalovala, da slovensko ne zna boljše. Toda Alma Karlin ni bila vzgojena v slovenskem nacionalnem duhu, čeprav sta bila oba starša Slovenca, temveč je jezik svojega pisanja izbrala povsem praktično - to ni bil njen materni jezik, slovenščina, temveč jezik njenega izobraževanja, nemščina, ki je polagoma pričela izpodrivati slovenščino. Nekaj podobnega se dogaja v sodobnosti s slovensko književnostjo v Avstriji - pisatelji in pisateljice, ki so slovenskega porekla, vedno več pišejo v nemščini. Danes gledamo na Almo Karlin kot na pisateljico z dvojno, to je z nemško-slovensko identiteto, kakršnih je bilo v 
slovenski zgodovini mnogo, saj smo Slovenci živeli v avstrijskem državnem okviru. V sodobnosti pa je najbrž premalo uzaveščeno dejstvo, da je bil ta prostor $\mathrm{v}$ resnici zelo dolgo $\mathrm{v}$ dvajseto stoletje dvojezičen in da so bili dvojezični tudi številni etablirani pisatelji in pisateljice, npr. tudi tisti, ki danes veljajo za »slovenske« (France Prešeren, Ivan Cankar, Zofka Kveder); dvojezični pa so bili ne nazadnje tudi znanstveniki, npr. Fran Miklošič, France Kidrič, Ivan Prijatelj, ali glasbeniki, npr. Hugo Wolf.

Med dela Alme Karlin, ki jih bralci še danes z zanimanjem prebirajo, nedvomno sodi obširno potopisno besedilo Samotno potovanje $v$ daljne dežele $\mathrm{s}$ podnaslovom Tragedija neke ženske (leta 2007 ga je v prevodu Mateje Ajdnik Korošec izdala Celjska Mohorjeva družba). Alma Karlin je v Predgovoru zapisala, da bo v tem delu poudarila le osebne izkušnje, in sicer izkušnje ženske, ki potuje sama, nadalje načine, kako je vedno znova sama zaslužila denar za potovanja, in da bo analizirala še vplive posameznih dežel na njeno psiho. $\mathrm{Na}$ začetku je samoironično zapisala, da je s svojih potovanj leta 1928 domov prinesla le samo sebe in svoj pisalni stroj, in to »oba v slabem stanju« (Karlin 2007: 5). Taka zabavna, samoironična perspektiva pa je značilna za vse njeno delo že od začetka, na katerem piše:

Sem edini otrok svoje matere in moji sorodniki so $\mathrm{z}$ večino glasov vedno trdili, da je omejitev na en primerek vsekakor treba razumeti kot nedvoumen blagoslov. Razen tega sem, kar je nadaljnja obremenilna okoliščina, tudi pisateljica (Karlin 2007: 7).

Nadalje omenja, da je leta 1919 prodala svoj prvi roman, pred tem pa se je obsedeno učila tujih jezikov pa tudi slikanja ter sanjala o potovanjih: »Bledla sem zaradi lastne veličine, se videla v vlogi modernega Kolumba, kako odkrivam novi svet« (Karlin 2007: 7). Omenja tudi svojo naivnost in napačne predstave na začetku potovanja: »Svet sem si zamišljala kot Evropo « (Karlin 2007: 8); ta opomba pa ni nepomembna, saj je v njenem okviru mogoče razumeti izrazito evropocentrično opazovanje sveta Alme Karlin, tudi pozneje, ko je že spoznala marsikaj tujega in drugačnega, a je vse dogodke, tudi neprijetne, spremljala predvsem kot Evropejka.

Karlinova se je odločila, da bo najprej odpotovala v Južno Ameriko, cilj njenega potovanja pa je bila Japonska. Posamezna poglavja nosijo naslov po mestih, ki jih je obiskala (Celje, pozneje Genova, Barcelona, Trinidad, Puerto Colombia itd.). Toda že na začetku poti, v Benetkah, se je zavedla svoje samote, čeprav takrat seveda še ni mogla vedeti, da jo bo poleg osamljenosti na njeni poti doletelo še vse mogoče, od spanja v podpalubju med množico ljudi pa do tega, da jo bodo okradli, poskušali posiliti, da bo velikokrat lačna, prezebla in bolna, okužena z nalezljivimi boleznimi. Toda njena ironija ostaja nemoteno prisotna tudi takrat, ko popisuje svoja najbolj žalostna stanja - o svoji lakoti pripominja, da je imela »kanibalske aspiracije «, ob pogledu na tretji razred na ladji, s katero je nameravala potovati, pa piše, da ji je "padla čeljust na prsi«, sebe imenuje "pravo evropsko gosko«, nepripravljeno na preizkušnje tega potovanja, ki si ga je sama izbrala. $Z$ duhovitimi pripombami je posuto vse njeno 
besedilo - ko neki Perujec pretepa ženo, Alma zapiše, da je to »zakonska masaža« (Karlin 2007: 34). Na zares številnih mestih se je Alma Karlin razodevala kot izjemno duhovita, a tudi ostra in lucidna opazovalka (Karlin 2007: 57, 58); posebne ironične duhovitosti, a tudi evropocentričnega pogleda, pa so deležni moški tujih ras, ki jih je srečevala na svoji poti, npr. v poglavju Guayaquil:

Slučajno sem pogledala čez mroža k oknu in videla, kako majhno odprtino zapolnjuje najgrši obraz, ki me je kdaj navdal z grozo. Rjava spaka, obdana z debelimi, nepočesanimi, črnimi lasmi, usta, ki so segala od ušesa do ušesa, nos kot ponošena moška copata, štrleče ličnice $\mathrm{v}$ rdečerjavih visečih licih in sredi te neprijetne mesene gmote dvoje črnih oči, v katerih se je lesketala sla kot pri lačni pumi. In ta pojava mi je dejala v ostro zveneči španščini: »Ljubim te! « in po kratkem premoru ob pogledu na gole ženske: »Vse vas ljubim!« (Karlin 2007: 68)

Moške, ki so jo nadlegovali, tudi sicer neprijazno poimenuje - »ekvatorska opica«, »opičji sin«, včasih pa piše kar o »moških dvonožcih«, o »živalih«; zaradi poskusa posilstva v Peruju npr. zapiše: »vendar mi je vse življenje ostal strah pred moško človeško živaljo« (Karlin 2007: 87).

Zanimiva pa so tudi mesta, ko razmišlja o sebi kot ženski, tudi v kontekstu prejšnjega dogodka: »vendar pišem kot ženska in za žensko je telo nedotakljiva svetinja« (Karlin 2007: 93).

Alma Karlin pa se je prav dobro zavedala svoje posebnosti in nenavadnosti, zlasti glede na merila dobe, v kateri je živela. Zato se je zavestno odločila za nekakšen celibat, ki se ji je zdel potreben za to, da bi lahko vse svoje bivanje posvetila pisanju: »Moje bivanje je pripadalo peresu« (Karlin 2007: 93-94). Zavedala se je, da je samotno potovanje za žensko v njenih časih nekaj čudnega, če ne tudi moralno vprašljivega, in navedla misli nekega Italijana, ki ga je srečala na svoji poti, na ladji Bologna: »Imam hčerko, a če bi hotela potovati kot vi, bi jo ustrelil. Raje to, kot da bi imela tako življenje« (Karlin 2007: 100).

V svetu, ki ga je najprej spoznavala (Peru), je bila zgrožena nad nasiljem, ki so ga bile deležne ženske in ki je bilo samoumevni del življenja. Sama se je skrivala za kratko, fantovsko frizuro, včasih pa tudi za moško obleko. O sebi je zapisala: »Umetnost mi je pomenila vse.« In v tem duhu je sledila svoji neizmerni želji po pisanju s potovanj ter razveseljevanju bralcev s podobami iz tujih, zanje neznanih kultur.

Toda čeprav je o ženskah in njihovem življenju, pa tudi o sebi, na poti velikokrat razmišljala, njenih zapisov vseeno ne moremo razumeti kot dela njene feministične ozaveščenosti, temveč zgolj kot odseve osebnih izkušenj in prepričanj. Karlinova ni nikjer zapisala, da bi se moral položaj za ženske v svetu kakor koli spremeniti, temveč se je le zavedala, da je zanje »povsod hudo«, ni pa zmogla nikakršne refleksije takih položajev. Večkrat je na primer razmišljala o težavah samotnega ženskega potovanja, a je ostala le pri tem, da je svoje bralke posvarila, naj se ne podajajo brezglavo kot ona v podobne nevarnosti, ker da vidijo drugi v njej le »vohunko ali pokvarjeno pustolovko « (Karlin 2007: 127). Njeni zapisi so zelo živi, slikoviti in živahni, pogosto prepleteni tudi s poudarjeno perspektivo ženske, vendar ostajajo brez slehernega feminističnega 
naboja, čeprav je bila prav ona tista, ki je v svojem času rušila klišeizirano podobo dobro vzgojene, neizobražene in predvsem pasivne ženske. Na svoji poti je morala sama zaslužiti za življenje, nikogar ni imela, ki bi jo podpiral; pisateljevala je in slikala, iskala najrazličnejše službe, v Panami je ustanovila celo prevajalsko pisarno, poučevala je itd. ter nenehno razmišljala o položaju žensk, vendar brez agitacije za njihove pravice. Glede odnosa med moškim in žensko v sodobnem svetu pa se je zadovoljila z ironičnimi pripombami, kakršna je tale: »Metoda jamskega človeka, ki je soprogo pobil s kijem na tla, da bi jo posedoval, ženske dvajsetega stoletja ne očara (ali omami) več« (Karlin 2007: 154). Svoje potovanje je imenovala »študijsko potovanje«, od nekega avstrijskega urednika časopisa, za katerega je pisala, pa je dobila pismo, naslovljeno kot »Dragi gospod Karlin!«. Ta na videz drobna peripetija pa seveda prav dobro priča o tem, kako nenavadna je bila odločitev Alme Karlin, da kot ženska živi življenje, kakršnega si je izbrala v času, ko njene vrstnice v Evropi v glavnem še niti pomislile niso, da bi zapustile domače vasi, študirale na tujih univerzah in same potovale po svetu. To dejstvo tem bolje razumemo na mestu, ko Alma Karlin omenja svoje izkušnje z ljudožerci, ki so v njenem času še dejavno bivali na nekaterih indonezijskih otokih, ki jih je obiskala (Karlin 2007: 338-339). Da je svet opazovala evropocentrično, pričajo nekatere njene opazke, ki bi jih v kontekstu današnjih meril imeli za rasistične (pripadnike drugih ras je imenovala »divjaki«, nasprotovala je rasno mešanim zakonom in večkrat omenila, da je vesela, ker je belka; Karlin 2007: 379-380). Zavedala se je svoje nenavadne osebnosti in kljub vsemu uživala $\mathrm{v}$ dinamičnem, čeravno tudi težkem načinu življenja, ki si ga je izbrala. A v Avstraliji, kamor je pripotovala, je o svojih popotovanjih tudi predavala ter zapisala: »Enkrat v goščavi, potem na govorniškem odru, nato pri divjakih in uro kasneje med velikimi borkami za ženske pravice« (Karlin 2007: 388).

Zelo navdušeno je pisala o tujih šegah in navadah, položaj žensk v tujih kulturah pa je popisovala in komentirala, ne da bi se zavedala, da so njeni nazori vsaj rahlo feministično osveščeni. O ženskah v Mandžuriji je npr. zapisala, da zavzemajo tamkajšnje delavke na polju "poseben položaj, ker so bolj svobodne in svojega moža ne častijo, kakor da je sveto bitje« (Karlin 2007: 320), o svojem položaju svobodne ženske pa npr.: »Imela sem hrano, ne da bi morala zanjo opravljati kakšne posebne obveznosti. Soproge kavalirjev pa so morale za te majhne ljubeznivosti kasneje prati umazane srajce in hlače svojih soprogov« (Karlin 2007: 33).

Nekatere njene opombe, ki so nastajale pri opazovanju odnosov med ženskami in moškimi v tujih deželah, npr. v Koreji, so polne humorja: »Nezadovoljne ženske imajo navado, da svoje neposlušne može povlečejo za čop, ki ga nosijo na vrhu glave. Morda bi tudi pri nas uvedli ta običaj?« (Karlin 2007: 272).

Toda kadar omenja otroško prostitucijo, na primer na Tajvanu, piše o tem pojavu kot opazovalka, hladno in neprizadeto. Zgrožena pa je nad fizično zlorabo otrok, npr. v Panamskem prekopu: »Z njima so ravnali kot z živino, tepli so ju z bičem in priganjali k vsakršnemu delu« (Karlin 2007: 124). 
Alma Karlin je ostala do današnjih dni posebna pa tudi kontroverzna pisateljska osebnost. Kljub temu da se je v osemdesetih letih prejšnjega stoletja zgodila nekakšna rehabilitacija te pisateljice in njenega dela, tako da se je povečalo literarnozgodovinsko in tudi bralsko zanimanje zanjo, se vendar še vedno sprašujemo, ali je »naša ali ni«. Mislim, da predstavlja značilen primer dvojne osebne pa tudi pisateljske identitete, obenem pa zanimiv vzorec nemško-slovenske medkulturnosti. Njen pravi materni jezik je bila slovenščina, njena mati pa je kot učiteljica celo veljala za narodno osveščevalko. Toda Alma vsekakor ni bila vzgojena v smislu slovenske narodne samozavesti, temveč je samoumevno pristala na nemščino kot prevladujoči jezik izobražencev. V potopisu Samotno potovanje večkrat, tudi v ironičnem kontekstu, omenja svojo identiteto, »državljanskost«, svojo državno pripadnost: še med prvo svetovno vojno je bila državljanka Avstro-Ogrske, po njej pa, ne da bi si to sama izbrala, državljanka Kraljevine Jugoslavije oz. države SHS. Toda po drugi svetovni vojni je, spet ironično, postala - ponovno ne po lastni izbiri - državljanka Socialistične republike Jugoslavije, glede na kraj bivanja, to je Celje, pa tudi Slovenka. O tem, kako sta jo čas in viharna zgodovina po svoje prestavljala, je zapisala:

Potem ko sem preživela začetek vojne v sovražnikovi deželi - v Londonu, eno leto na Norveškem in eno na Švedskem ter se potem vrnila skozi zavezniško Nemčijo v Avstrijo in tu gledala vso vojno bedo, sem postala skoraj brez vednosti in volje državljanka tuje države. (Karlin 2007: 8)

Podoben primer zmede, ki se nanaša na njeno identiteto, je omenila ob dogodkih na ladji, preden je skupaj z drugimi »Nemci« pripotovala v Panamo:

Organi oblasti so šepetali med seboj kot ob primeru smrti in ujela sem le eno besedo: »Nemci.« To je zadostovalo. Vedela sem, da je naša usoda na tehtnici. Vsekakor sem imela vizum za Panamo, ki ga večina ni imela, in počutila sem se varno. S tem in $\mathrm{s}$ potnim listom »kralja Petra po božji milosti«, ki ga ni nihče razumel, verjetno niti sam kralj ne, ker so bile določene stvari vpisane v slovenščini, sem bila vzvišena nad vso policijo, če bi me slučajno osumili, da sem boljševik, anarhist, idealist ali drug "gnoj«. (Karlin 2007: 57)

O tem, kako zmeden je bil njen položaj, pričajo še nekateri zapisi, na primer na mestu, ko je po končani prvi svetovni vojni že posedovala potni list države SHS, a je o sebi razmišljala kot o »nemški pisateljici« (Karlin 2007: 27), spet na drugem mestu se je imenovala »nekdanjo Avstrijko« in omenila, da se ne more zbližati ne z Nemci ne z Avstrijci pa tudi s Francozi ne; čutila se je izločeno iz kolektiva (Karlin 2007: 92). Na Kitajskem je o sebi zapisala, da je »Avstrijka«, in pripisala: »kar dejansko ni več povsem držalo« (Karlin 2007: 282). Ko se je nahajala na Japonskem, pa se je imenovala »Jugoslovanko«, pri čemer je svoja dela izdajala pri nemških založbah in kljub svojemu »jugoslovanstvu« dobila delo na nemškem veleposlaništvu (Karlin 2007: 247). Toda vsa se je posvečala raziskovanju in pisanju, pisala je za triindvajset časopisov in revij, ki so izhajale deloma v Nemčiji, deloma v Avstriji, v času svojega bivanja v Pekingu pa je pripravljala še zbirko novel; na Tajvanu si je zapisovala njihove pravljice in 
sage, domov je pošiljala hrošče in školjke, skratka, vprašanja o njeni nacionalni pripadnosti je niso vznemirjala.

Splošen vtis glede tega vprašanja pa je, da si Alma Karlin v zvezi s svojo identiteto ni belila glave in da se je s takimi vprašanji ukvarjala predvsem takrat, kadar je bila vanje prisiljena - iz praktičnih razlogov ob začetkih obeh svetovnih vojn, nekoliko med njima in rahlo po drugi svetovni vojni. Kot nemško pišoča avtorica je imela dostop do objav v svetovnih revijah in časopisih in s tem je bila zelo zadovoljna, kot slovensko pišočo avtorico pa je zagotovo nihče $v$ tedanji Evropi še opazil ne bi. Namesto da bi razmišljala o svoji nacionalni ali državljanski pripadnosti, je večkrat pretresljivo razmišljala o lastnem položaju v svetu in se kljub pisateljski popularnosti zavedala svoje popolne izločenosti in samote:

Medla naklonjenost prebivalcev celega sveta ne odtehta ljubezni enega samega človeka; nikogar nisem ljubila in nihče na svetu ni ljubil mene - ne otrok, ne ženska, ne moški. Mislim, v taki meri, kot bi si sama želela, in tako sem hodila po zemeljski krogli gor in dol kakor kotaleči se kamen, ki se ga ni prijel noben mah. Bila sem popolnoma nevezana in popolnoma osamljena. Čim sem se z nekom spoprijateljila, sem morala dalje. Tako je bilo v moji rani mladosti, tako je bilo na potovanju $\mathrm{v}$ daljne dežele in vedno bo tako. (Karlin 2007: 266)

Alma Karlin je bila kot zanimiva pisateljska osebnost med najbolj branimi pisateljicami svojega časa. Še danes vzbuja občudovanje njen občutek za oblikovanje zanimive zgodbe. Takih literarnih mest je v njenih potopisih mnogo, tak je npr. opis božiča v Panami pa opisi hoje po pragozdu v San Salvadorju, njene zgodbe so poleg vsega še duhovite in polne presenečenj. Opazno je, da je pisala za bralca, za nekoga, pri katerem je skušala vzbuditi pozornost. Od tod njeni ironični komentarji, natančne slike, pospremljene tako s tragičnimi kakor komičnimi dogodki. Tudi dialogi, ki jih je oblikovala, so živi, na nobenem mestu dolgočasni ali umetni. Opaziti je njeno nagnjenost k mistiki, ki jo vpleta v svoja razmišljanja (Urok Južnega morja; tu je mističnost celo v naslovu). Poudarjala je moč duha in svojo naklonjenost Vzhodu:

Aktivni zahod se kakor otrok navdušuje nad svojo telesno močjo; razmišljujoči, vase poglobljeni Vzhod pa išče moč duha; telo je zgolj njegov zunanji izraz in začasni pomočnik, ki mu služi za posodo (Karlin 2007a: 233).

Evropa, v kateri je živela in objavila glavnino svojih del, pa je bila daleč od take »moči duha«. V njej se je vzpenjal fašizem, kar se je udejanjilo z začetkom in nadaljevanjem druge svetovne vojne. Alma Karlin je bila aktivna nasprotnica fašizma, pozneje tudi njegova žrtev. Njeno trdno življenjsko vodilo, da ostane predvsem pisateljica, in občutek za pravičnost ter prepoznavanje pravega zla, ki je ogrožalo Evropo, pa jo uvrščata med najizrazitejše, čeprav tudi samosvoje in posebne osebnosti, ki so zaznamovale 20. stoletje. Ostala je zvesta sami sebi in svojemu človeškemu prepričanju, kar pa za žensko njenega časa ni bilo niti malo lahko. 


\section{VIRI IN LITERATURA}

Alma M. KARLIN, 2007: Samotno potovanje. Celje: Celjska Mohorjeva družba.

- -, 2007a: Moji zgubljeni topoli. Ljubljana: Mladinska knjiga; Celje: Muzej novejše zgodovine.

Silvija BOROVNIK, 1998: Upornica zoper ženske stereotipe. Študije in drobiž. Ravne na Koroškem: Založba Voranc.

Andreja JEZERNIK, 2009: Alma M. Karlin: državljanka sveta. Ljubljana: Mladinska knjiga.

Tone KREGAR, 2007: Almino potovanje med Nemci in Slovenci. Moji zgubljeni topoli. Ljubljana: Mladinska knjiga; Celje: Muzej novejše zgodovine. 11-25.

Marijan PUŠAVEC, 2007: Alma M. Karlin in Einsame Weltreise. Samotno potovanje. Celje: Celjska Mohorjeva družba. 421-431.

\section{ALMA KARLIN - AN EXTRAORDINARY WRITER}

This article presents Alma Karlin as a peculiar person and a writer. First, she was a woman who broke down stereotypes of her time with her unusual life path. Furthermore, she was a very prolific and popular author before the Second World War. This article demonstrates her gift for forming compelling and readable stories, her sense of irony and self-irony as well as her distinctive Eurocentric world view. In this article she is discussed as a typical representative of the German-Slovenian intercultural identity. 